\title{
Association of statistics with biostatistics Research
}

\begin{abstract}
Research is means of extracting/inventing of knowledge in any subject while statistics has become an essential and unavoidable component of scientific investigation and research not only in the branches of science but also in the other fields where data are dealt with. On the other hand, biostatistics research has been observed to play significant role in the research and investigation in bioscience, life science, biology and many others. This paper describes (i) the role of statistics and of biostatistics, (ii) the idea of research in general \& of research in biostatistics specifically and (iii) the association of statistics with research in general and with research in biostatistics research specifically.
\end{abstract}

Keywords: Statistics, biostatistics, research, basic role, association
Volume 8 Issue 4 - 2019

\author{
Dhritikesh Chakrabarty \\ Department of Statistics, Gauhati University, India
}

Correspondence: Dhritikesh Chakrabarty, Department of Statistics, Handique Girls' College, Gauhati University, Guwahati -78100।,Assam, India, Email dhritikesh.c@rediffmail.com

Received: April 27, 2018 | Published: July 0I, 2019

\section{Introduction}

The history of the beginning of the development of the theory of statistics had been lost in the dust of antiquity. ${ }^{1-5}$ It has been found that statistics in ancient times was used by the governments in keeping records related to administrative matters like birth, death, population, etc. while it has been found that John Grant is the first man to make study on birth, death, expectation of life etc. from statistical point of view in the 17 th century. ${ }^{6}$ Statistics now has been found to be a major player in playing the role of understanding various phenomena in almost every branch of science. At the current stage of human civilization, statistics has become an unavoidable and essential analytical tool for scientific research. ${ }^{7,8}$ The discipline of biostatistics ${ }^{9-15}$ has been developed for the interest of research in bioscience, life science, biology and some allied fields.

The above facts imply that there is necessity of study on the association of statistics in bioscience research. The discipline of biostatistics has been developed due to the need of statistical methods especially for bioscience research. In pursuance of this necessity, attempt has here been made on searching for the association of statistics with research in general and specifically with bioscience research. In this paper, discussion has been made on

a) The role of statistics and of biostatistics

b) The idea of research in general \& of research in biostatistics specifically and

c) The association of statistics with research in general and with research in biostatistics research specifically.

\section{Statistics-its identity}

\section{Meaning}

There had been several researches on the history of the development of statistics ${ }^{16-21}$ so far. From these researches, three possibilities have been obtained regarding the derivation of the word "Statistics" which can be stated as follows: "The word "Statistics" has come from the Latin word "status" or Italian word "statista" or the German word "Statistik" each of which means a political state." $16-21$ The word "Statistics" was used as a term to describe the practice of collection of information, by the state authority, on births and deaths more than 300 years ago. ${ }^{16,18,21-23}$

At the current stage, two words namely "Statistics" and "Statistic" are used in the theory of statistics. The word "Statistics" is used to mean data/information on events, phenomena, experiments etc. On the other hand, the word "Statistic" is used to mean the method of operation on data. The word "Statistic" is used to mean the function of data applied in determination problem (termed as "estimation") and in testing problem (termed as "hypothesis testing").

\section{Definition}

Statistics had been defined differently at different time. The definitions of statistics composed so far, can be explained as to be composed by two ways namely (A) definition as statistical data and (B) definition as statistical method.

\section{A. Definitions as statistical data}

1. Statistics has been described, as data/information, by the following definitions. ${ }^{2-4,16}$

2. Webster's Definition: Statistics are the classified facts representing the conditions of the people in a state, especially those facts which can be stated in numbers or any tabular or classified arrangement.

3. Definition due to Yule and Kendall: Statistics means quantitative data affected to a marked extent by multiplicity of causes.

4. Bowley's Definition: Statistics are Numerical Statements of facts in any department of enquiry placed in relation to each other.

5. Definition by Prof. Horace Secrist: Statistics means aggregates of facts affected to a marked extent by multiplicity of causes, numerically expressed, enumerated or estimated according to reasonable standards of accuracy, collected in a systematic manner for a predetermined purpose and placed in relation to each other.

\section{B. Definitions as statistical method}

1. Statistics has been described, as statistical method, by the following definitions. ${ }^{2,3,16}$

2. Bowley's Definition: Statistics can be defined to be the science of (i) counting, (ii) averages \& (iii) measurement of social organism.

3. Boddington's Definition: Statistics is the Science of Estimates and Probabilities.

4. King's Definition: The science of statistics is the method of 
judging collective, natural or social phenomena from the analysis or enumeration or collection of estimates

5. Lovitt's Definition: The science of statistics is the method of judging collective, natural or social phenomena from the analysis or enumeration or collection of estimates.

6. Definition by Croxton and Cowden: Statistics is the science which deals with the collection, analysis and interpretation of numerical data.

7. At present, this definition of statistics has been regarded as its universally accepted definition.

\section{Jobs in statistics}

a) The works/jobs to be done in statistical science ${ }^{7}$ can be classified into the following stages:

b) Collection of Data: In this stage, data/information/observations required under study are collected.

c) Scrutiny of Data: Data/information/observations collected, in stage 1 , are verified/scrutinized In this stage.

d) Classification of Data: Verified/scrutinized data are classified according to requirement/convenience are classified/tabulated In this stage.

e) Analysis of Data: In this stage, classified/tabulated data are analyzed.

f) Interpretation of Results: Results/outcomes/findings obtained in the earlier stage, are interpreted In this stage.

g) Drawing of Conclusion/Inference: Based on the results/ outcomes/findings and interpretations obtained in the earlier two stages, conclusions/inferences are drawn in this stage.

h) Note: Observing the six stages, one can interpret that jobs to be done in statistical science can be broadly treated as three-stage jobs namely Collection Stage, Classification Stage (comprising Scrutiny of Data \& Classification of Data) and Analysis Stage (comprising of Interpretation of Results/Findings \& Drawing of Conclusion).

\section{Biostatistics -its identity}

a) Biostatistics is closely associated to bioscience. The idea and concept of bioscience ${ }^{6,24-29}$ can be expressed by the following three points:

b) Any of the branches of natural science dealing with the structure and behavior of living organisms is bioscience (or life science).

c) Bioscience is the broad term for any type of science dealing with life, like botany, biology, medical, or health science. Genetics, immunology, and biochemistry would also fit in this category.

d) Bioscience is the study of biology wherein all the applicable sciences (physics, chemistry, etc.) are applied.

e) Each of the branches namely Natural science, Biological science (\& also known as biology), Euthenics, Cacogenics (\& also dysgenics), Eugenics, Dietetics, Dermatoglyphics, Craniology, Biometrics (also Biometry \& Biostatistics), Biomedical science, Medical science etc. is a kind of bioscience. Biology ${ }^{26,29}$ one prime field of bioscience, is a natural science concerned with the study of life and living organisms.

\section{Meaning of biostatistics}

a) Meaning, idea and concept of biostatistics are available in many literature. ${ }^{9,10,12,13,30-33}$

b) The following points express the identity of biostatistics:

c) Biostatistics can be interpreted as a branch of statistics and also as a branch of bioscience in general ( $\&$ in biology in particular) that is concerned with the application of statistics to the topics in biology.

d) Biostatistics is a branch of statistics responsible for the proper interpretation of scientific data in the field of bioscience in general ( $\&$ in biology in particular).

e) Biostatistics is a branch of statistics that deals with collection of data, scrutiny of collected data, classification \& representation of scrutinized data, analysis of scrutinized data, interpretation of findings of analysis and drawing of conclusion, recommendation etc. in the field of bioscience in general ( $\&$ in biology in particular).

f) Biostatistics is a branch of statistics that is concerned with the conversion of data/observations/information in the field of bioscience in to knowledge. Berger \& Matthews ${ }^{30}$ defined it as follows:

g) "Biostatistics is the discipline concerned with how we ought to make decisions when analyzing biomedical data. It is the evolving discipline concerned with formulating explicit rules to compensate both for the fallibility of human intuition in general and for biases in study design in particular." On the other hand, Reichenbach ${ }^{6}$ defined biostatistics as follows: "Biostatistics is the application of statistical techniques to scientific research in health-related fields, including medicine and public health."

\section{Research in general \& in biostatistics}

\section{Meaning of Research}

1. Meaning, idea and concept of research are available in many literature. ${ }^{7,8,11,12,34-41}$ Following are some points that can express the meaning of research:

2. Research means the activities done for searching for new knowledge, new facts, replies to various queries and solutions to the various problems.

3. The word "research" can be interpreted as a number of similar and often overlapping activities involving a search for information.

4. Activities done for reviewing the existing knowledge, facts, theories etc. can also be called research.

5. Reestablishing of the existing knowledge, facts, theories etc. can also be interpreted as research.

6. Evaluating the existing knowledge, facts, theories etc. can also be interpreted as research.

\section{Each of the activities namely}

Searching for of new information/knowledge, Creation of new information/knowledge, Use of existing information/knowledge, Review of existing information/knowledge, Evaluation of existing information/knowledge, Investigation of phenomena, Establishing and/or reestablishing of some fact, Analyzing information/data to 
draw new conclusions, Discover and/or invent new information/ knowledge, Modification and/or extension of existing theory, Interpretation of facts, Revision of accepted theories can be regarded as research activity.

\section{Classification of research}

Researches can be classified in different ways. Some types of

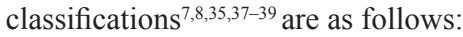

Types of Research based on First Way of Classification

In the first thinking, researches can be classified into two broad types namely

1. Theoretical type of researches

2. Applied type of researches

Theoretical researches can again be classified into three subclasses namely

i. Conceptual type of researches,

ii. Theory development type of researches

iii. Methodological type of researches

Similarly, applied types of researches can be classified into two subclasses namely

i. Art of application (methodological in other words) type of researches

ii. Application in real situation (reality) type of researches

Types of research based on second way of classification

On the basis of the experimentation involved, researches can be classified into two broad types namely

(i) Experimental type of researches

(ii) Non-experimental type of researches

Experimental type of researches can be classified into two subclasses. They are

(i) Theory-development type of researches

(ii) Applied type of researches

Similarly, non-experimental type of researches can also be classified into two subclasses which are

(i) Theory-development type of researches

(ii) Applied type of researches respectively.

Types of research based on third way of classification

On the basis of the dependence of one research upon another, researches can be classified into four broad types namely
i. Original type of researches
ii. Extension type of researches
iii. Modification type of researches
iv. Application of existing theory type of researches

Types of research based on fourth way of classification

On the basis of the methods applied, researcher can be classified as follows:

1. Observational research which is again of two types namely naturalistic observational research and laboratory observation research.

2. Case Study research which is again of two types namely individual case study and group of individuals case study.

3. Survey research which is based on survey method.

4. Experimental Research which are based on experiment either in laboratory or otherwise.

5. Observational trials which are the researches related to health issue.

6. Delphi research which is based on Delphi method.

7. Content analysis.

\section{Some other types}

There are some more and more types of researches..$^{7,8,37-39}$ some of them are as follows:

1) Basic Research (also known as "fundamental research" or "pure research") which refers to discover basic truths or principles.

2) Applied Research which refers to seeking new applications of scientific knowledge to the solution of a problem.

3) Developmental Research which refers to decision-oriented research involving the application of knowledge in response to an immediate need to improve existing ones.

4) Library Research which is conducted in the library.

5) Field Research which is conducted in field (more specifically in natural setting).

6) Laboratory Research which is conducted in artificial or controlled conditions.

7) Quantitative Research which is associated to quantitative characteristic.

8) Qualitative Research which is associated to qualitative characteristic.

9) Mixed research which combines qualitative research and quantitative research into one single research.

10) Action research that follows accomplishment and studying at the same time.

\section{Steps in research process}

The research process is the step-by-step procedure of developing research. There is difference among the various opinions on the steps of research process. The usual eight steps of the research process, ${ }^{34,35,39}$ arranged in the order in which the items of the work in the research are to be performed, are as follows:

\section{Step I: Identification of the problem}

This step consists of 
i. Observation of the problem,

ii. Identification of the problem,

iii. Selection of the problem,

iv. Setting up of the objective.

v. Setting up of hypothesis if any.

\section{Step 2: Review of the literature}

This step consists of

i. Learning more about the topic under investigation,

ii. Searching of the literature related to the research problem and needed in the problem,

iii. Learning the literature related to the research problem and needed in the problem

iv. Converting the literature, if needed, in to the form suitable to be applied in research

\section{Step 3: Clarification of the problem}

This step consists of

i. Clarification of the problem if needed,

ii. Narrowing the scope of study with the help of review of literature.

\section{Step 4: Definition of terms and concepts}

This step consists of

i. Defining the terms and concepts introduced/to be applied in the study,

ii. Mentioning/explaining/describing the meaning of the abbreviations, symbols and notations to be used in the study.

\section{Step 5: Definition of the population}

This step consists of

i. Identifying the group of individuals and/or of the objects (called population) on which the research is focused,

ii. Defining the population and sampling unit (if required) to be involved in the Research

\section{Step 6: Development of the instrumentation plan}

This step is nothing but an algorithm i.e. flow chart of the actual items to be executed in the entire path of the research. This step consists of

i. Planning the experiment for experimental research (or the survey for survey type of research or otherwise) needed,

ii. Constructing the design of experiment for experimental research (or the design of survey for survey type of research or the other design of research) suitable for the research,

iii. Selection of space (location) and time for performing experiment or conducting survey or otherwise,

iv. Preparing for execution of the design constructed

v. Selection of type(s) and size (number) of data/observations to be searched for

\section{Step 7: Collection of data}

This step is the beginning of the actual works of the research. This step consists of

i. Execution of the design constructed making observation(s) on the experiment for experimental research (or seeking response from the individuals in the sample for survey type of research or otherwise),

ii. Making observation(s) on the experiment for experimental research (or seeking response from the individuals in the sample for survey type of research or otherwise),

iii. Noting down/recording the observation(s) obtained for experimental research (or response(s) obtained for survey type of research or otherwise).

\section{Step 8:Analysis of data}

\section{This step consists of}

i. Scrutiny of data collected in the earlier step,

ii. Representation of scrutinized data,

iii. Selection of statistical method(s) to be applied in analysis of data,

iv. Formatting the data to be make suitable for analysis

v. Actual analysis of data

vi. Drawing of conclusion(s), recommendation(s), prescription(s) etc.

\section{Biostatistics research: steps of works}

It follows from the steps associated to research process ${ }^{34,35,39}$ and from the jobs to be done in research, ${ }^{7}$ the steps works to be done in biostatistics research can be arranged in the following order:

1. Association to Problem: In the first step, researcher/investigator requires to be associated with the problem existing in the field of interest.

2. Detection of Problem (for imposed research)/Fixing of Problem (for own research, thrust, adventure etc.): In the next step, researcher/investigator requires to detect the problem(s) existing in the field of interest which need(s) research/investigation.

3. Fixing/Setting of Objective: In this step, researcher/investigator requires to fix problem(s) and to set the objective(s) for study.

4. Setting up of Hypothesis if any: Here, the hypothesis to be tested is to be framed of. Normally, a null hypothesis is framed of against an alternative hypothesis with a level of significance (and also with power of the test if necessary).

5. Perform Experimentation (for Experimental Research)/Search for Logic/Derivation Method (for Theoretical Research): In this step, experimentation is performed or survey is conducted depending upon the requirement if the research is of experimental type. For theoretical research, logic for (or method of derivation of) development of theory is searched for in this step.

6. Collection of Information/Observation/Data: In this step, data/ observation/information is collected for experimental research.

7. Scrutiny of Data: The jobs in this step consist of 
i. Detection of Necessary Data \& Unnecessary Data etc.,

ii. Remove Unnecessary/Irrelevant Data,

iii. Verification of Error(s) in Data,

iv. Correct Error(s) from Data (having Error) if Possible,

v. Remove Data having Error(s) if Not Possible to Correct,

vi. Detect Qualified Observation/Data (for Analysis),

vii. Detect Unqualified Observation/Data (Not to be used in Analysis).

8. Data/observation/information, Tabulation of data/observation/ information, Conversion of form of data/observation/information from the form in collection to the required form is to be done in this step.

9. Analysis of Data: Analysis of data/observation/information is to be done in this step. The two broad aspects of analysis are determination (estimation in statistical terminology) and testing of hypothesis.

10. Interpretation of Results: Results/outcomes/findings obtained in the earlier stage, are interpreted in this stage.

11. Drawing of Conclusion: Based on the results/outcomes/findings and interpretations obtained in the earlier two stages, conclusions/ inferences are drawn in this stage.

\section{Concluding remark}

The works to be done in biostatistics research and the jobs to be done in statistics have been found to be similar. Thus, statistics is fully associated to biostatistics research. Also, in any biostatistics research the following items of woks cannot be performed without the help of statistical method(s): Scrutiny of data, Classification and representation of scrutinized data, Analysis of scrutinized data, Interpretation of findings of analysis, Drawing of conclusion/inference \& Prescription, recommendation etc. That is why statistics can be regarded as essential and unavoidable tool of biostatistics research. The development of biostatistics progresses with the development of statistics and also with the development of bioscience due to the need of tools in bioscience research and conversely the development of statistics progresses due to the need of new and new statistical methods in biostatistics research.

\section{Acknowledgments}

None.

\section{Conflicts of interest}

The author declares there are no conflicts of interest.

\section{References}

1. Bayes T. Thomas Bays essay towards solving a problem in the doctrine of chances. Studies in the history of probability and statistics. Barnerd GA, editor. London; Biometrika; 1958:45(3/4);293-315.

2. Hayden Erika Check. Biostatistics: Revealing analysis. Nature. 2012;482(7384):263-265.

3. Kothari CR. Research Methodology Methods and Techniques. 2nd edition. 2006. 414 p.

4. Lappan G, Frey JT, Fizgerald WM, et al. Teacher's Guide Connected Mathematics: Samples and Populations. USA, CA: Dale Seymour Publications, 1988. 285 p.
5. Magner Lois N. A History of the Life Sciences, Revised and Expanded. India: CRC Press; 2002. 514 p.

6. Maistrov LE. Probability Theory A Historical sketch. New York and London: Academic Press: 1974. p.1-10.

7. Dhritikesh Chakrabarty. Understanding the Space of Research. Biostatistics and Biometrics Open Access Journal. 2018a;4(5):001-017.

8. Dhritikesh Chakrabarty. Statistics and Bioscience:Association in Research. Significances of Bioengineering \& Biosciences. 2018b;2(5):001-007.

9. Abhaya Indrayan. Medical Biostatistics. $4^{\text {th }}$ Edition. India: CRC Press; 2012. 994 p.

10. Hayden Erika Check. Biostatistics: Revealing analysis. Nature. 2012;482(7384):263-265.

11. Dhritikesh Chakrabarty. Statistics and Bioscience: Association in Research. Significances of Bioengineering \& Biosciences. 2018b;2(5):001-007.

12. Iverson MG, Gergen M. Statistics: The Conceptual Approach. Springer Verlag, New York; 1997.735 p.

13. Helen Causton, John Quackenbush, Alvis Brazma. Statistical Analysis of Gene Expression Microarray Data. Wiley Blackwell; 2003.128 p.

14. Wayne W Daniel. Biostatistics: Basic Concepts and Methodology for the Health Sciences. Wiley Series in Probability and Statistics. 2014. 968 p.

15. Weathington BL, Cunningham CJL, Pittenger DP. Research Methods for the Behavioral and Social Sciences. Hoboken, NJ: John Wiley \& Sons, Inc; $2010.672 \mathrm{p}$.

16. Donald H McBurney. Research Methods. $5^{\text {th }}$ Edition. Thomson Learning; 2006. $450 \mathrm{p}$.

17. Rohrer C. When to use which user experience research methods. Nielsen Norman Group. 2008.

18. Terry Speed. Microarray Gene Expression Data Analysis: A Beginner's Guide. Chapman \& Hall/CRC. 2003. 55 p.

19. Von Mises R. Probability and Statistics. New York: Academic Press; 1964. $641 \mathrm{p}$.

20. Von Mises R. Wahrscheinlichkeits Rechnung. 1931.

21. Von Mises R. Ueber Aufteilungsund Besetzungs-Wahrscheinlichkeiten. Revve de la Faculte des Sciences de. 1939;4(2):145-163.

22. Forthofer, Ronald N, Lee Eun Sul, et al. Introduction to Biostatistics. A Guide to Design, Analysis, and Discovery. USA: Academic Press; 1995. $567 \mathrm{p}$.

23. Geiringer H. Probability, Statistics and Truth. London: Allen and Unwin; 1957. $244 \mathrm{p}$.

24. Geiringer H. Mathematical Theory of Probability and Statistics. New York: Academic Press; 1964.708 p.

25. Landwehr JM, Watkins AE. Exploring Data. Palo Alto, CA: Dale Seymour Publications; 1995. 181 p.

26. Matthias Dehmer, Frank Emmert Streib, Armin Graber, et al. Applied Statistics for Network Biology: Methods in Systems Biology. Wiley Blackwell. 2011. 478 p.

27. Reichenbach H. Experience and Prediction: An Analysis of the Foundations and the Structure of Knowledge. Chicago; University of Chicago Press; 1938. 428 p.

28. Savage LJ. The Foundations of Statistics. New York: John Wiley; 1954. 294 p.

29. Stangor C. Research Methods for the Behavioral Sciences. 3rd edition. Boston, USA: Houghton Mifflin Company; 2007. 427 p. 
30. Berger VW, Matthews JR. What Does Biostatistics Mean To Us. Mens Sana Monogr. 2006;4(1):89-103.

31. Frank Emmert Streib \& Matthias Dehmer. Medical Biostatistics for Complex Diseases. USA: Wiley Blackwell; 2010. 412 p.

32. Von Mises R. Probability, Statistics and Truth. MacMillan; 1939.

33. Wayne W Daniel. Biostatistics: A foundation for Analysis in the Health Sciences.10th Edition. Wiley Series in Probability and Statistics. 2012. $960 \mathrm{p}$.

34. Terry Speed. Microarray Gene Expression Data Analysis: A Beginner's Guide. Chapman \& Hall/CRC. 2003. 55 p.

35. Von Mises R. Probability and Statistics. New York: Academic Press; 1964. $641 \mathrm{p}$
36. Iverson MG, Gergen M. Statistics: The Conceptual Approach. New York, USA: Springer-Verlag; 1997. $735 \mathrm{p}$.

37. Jackson SL. Research Methods and Statistics: A Critical Thinking Approach. 3rd edition. Belmont, CA: Wadsworth; 2009. 430 p.

38. Kaplan D. The Sage Handbook of Quantitative Methodology for Social Sciences. Sage Publications; 2004a.

39. Kaplan D. The Sage Handbook of Quantitative Methodology for Social Sciences. Sage Publications; 2004b.

40. Richards Robert J. The Romantic Conception of Life: Science and Philosophy in the Age of Goethe. Chicago: University of Chicago Press; 2002. $606 \mathrm{p}$.

41. Serafini Anthony. The Epic History of Biology. US: Springer; 2013. 395 p. 